of his balance is not excessive, and that in practice it will safely indicate the millionth of a grain.

One observation of the weight of sunlight is given; it was taken on December 13; but the sun was so obscured by thin clouds and haze that it was only equal to 10:2 candles 6 inches off. Calculating from this datum, it is seen that the pressure of sunshine is 2.3 tons per square mile.

The author promises further observations with this instrument, not only in photometry and in the repulsion caused by radiation, but in other branches of science in which the possession of a balance of such incredible delicacy is likely to furnish valuable results.

\section{SCIENCE IN GERMANY}

(From a German Correspondent.)

A FEW years ago Edlund attempted to decide the A question whether the galvanic current is capable of directly altering the volume of a conductor through which it flows, or not, i.e., whether changes of volume were demonstrable that were independent of the heat produced in the conducting wire? The results of his experiments appeared to furnish an affirmative answer to this question. More recently, Streintz published an investigation, the result of which was a confirmation of Edlund's view on the expanding power of the galvanic current. The expanding action found by Edlund was from 2.8 to 6.5 per cent. of the action of the heat simultaneously produced; that found by Streintz was considerably greater. In soft iron it amounted to 27 per cent. of the action of the heat.

From the fundamental importance which attaches to this question, in relation to the theory of galvanism, and from the difficulty of demonstrating the volume-changes referred to, apart from the actions of the heat simultaneously produced, it was desirable that the subject should be investigated by a method as free from error as possible. Such an investigation has lately been carried out by Herr Exner, in Vienra. The essential points of his method are as follows :-

Two pieces, $a$ and $b$, of the same wire, about equaliy long, were suspended vertically one over the other, as indicated schematically in the figure. The lower piece, $b$, passed centrally through a glass tube, $c$, which was quite open above, but closed below with a cork, which merely gave passage to the wire $b$ by a short glass tube

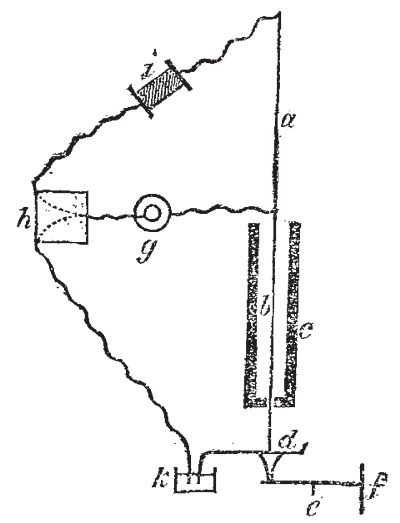

(2mm. wide) inserted in it. From the lower end of the wire $b$ hung the plate $d$ for holding weights. This was furnished at its base with a sharp iron point, meant to act on one arm of a lever which could be turned about $\varepsilon$, while the other arm bore the mirror $f$ at right-angles to its axis, and so in a vertical plane. If the image of a vertical scale were observed in this mirror with a telescope, $t^{3} c$ least change in length of the wires $a$ and $b$ could tho eby be perceived. From the point of con- nection between a and $\delta$ a wire was connected with the battery $g$. The other pole of the battery was connected with the commutator $h$, and thus the current could be sent either through the rheostat $i$ to the suspending point of the wire $a$ and through the latter back to the battery, or on the other side to the mercury cup. $k$, in which is dipped the bent end of a short copper wire soldered to the plate, $d$, establishing thus a conductive connection between the commutator $h$ and the wire $b$. Through the latter the current then went back to the battery. One could thus easily send the current successively through each of the two wire-pieces, $a$ and $b$, separately, and so observe the elongation experienced by each. Since, as has been said, the two pieces $a$ and $b$ were not exactly equal in length, their elongations were also not exactly equal; to make them equal, the rheostat $i$ was inserted, by which the resistance in the circuit $g h i a g$ was so regulated, that with unchanged battery the successively observed elongations of $a$ and $b$ were the same. Water was now allowed to pass through the glass tube $c$, in order to take away as much as possible of the heat produced in the wire $b$ by the galvanic current. If, now, the current passed through $b$, only the elongation which might occur independently of the heat action of the current would be observed, the heat produced being removed by the flowing water. ${ }^{1}$ If, however, the current passed through $a$, both an elongation produced in $a$ through direct action of the current, and the elongation through action of heat would be observed at the same time. [These experiments might of course also be made with only one piece of wire, e.g. b. The second piece $a$, serves only for making the obvervations more quickly in succession.]

It was found that the galvanic expansion expressed in percentage of the heat-expansion was only about $I^{\prime} 2$ to $2 \cdot 2$ per cent.; and no connection was recognisable with the nature of the metal employed. If it be considered that these values, of course, can only be an upper limit, it will follow from the smallness of the effect obtained that there is no suffient ground for the hypothesis of a special expansion-power of the galvanic current. There can hardly be any doubt that the slight expansion which the water-inclosed wire still shows is simply and alone due to the heat remaining in it.

W.

\section{THE INTERNATIONAL METRTC COMMIS. SION AT PARIS}

$\mathrm{IN}^{\mathrm{N}}$ previous numbers of $\mathrm{NATURE}^{2}$ some information has been given of the proceedings of the International Metric Commission of Paris, and of the progress of their work in providing new international standards of the metric system. The construction of the new standard metres and kilogrammes of platinum-iridium, which was entrusted to the French section of the Commission, is now approaching completion, and their comparisons with the old standards of the Archives and with each other will probably be commenced early this spring.

It has been already explained that the definitive ve rification of the new standards was entrusted by the Commission to a permanent committee of twelve of their members, each representing one of the principal civilised countries interested. For the purposes of providing the committee with the necessary means of exercising their duties, and of giving an authoritative international character to the new standards, and to the regulations to be adopted for the custody and use of the new international metric prototypes, a diplomatic conference was held at Paris in March 1875 , when a convention was entered into for effecting these objects.

Papers relating to the meeting and proceedings of this diplomatic conference, drawn up by Mr. Chisholm, the Warden of the Standards, who was the representative of I It may happen that the heat of the wire is not entirely carried off by the flowing water. 
Great Britain at the Conference, were laid before both Houses of Parliament last session by Her Majesty's command. Some further information upon the subject is contained in the Ninth Annual Report of the Warden of the Standards, recently published.

The following is a summary of the terms of the Convention," which bears date Paris, May 20, 1875.

By the two first Articles the high contracting parties agree to found and maintain at their common expense an International Bureau of Weights and Measures, scientific and permanent, its seat to be at Paris. The French Government will undertake to facilitate the acquisition, or if requisite, the construction of a building to be specially appropriated for this purpose.

Article 3 fixes the conditions under which the International Bureau will execute its functions. It is to be placed under the exclusive direction and superintendence of an International Committee of Weights and Measures, which itself is to be under the authority of a General Conference of Weights and Measures formed of delegates from all the contracting Governments.

The President for the time being of the Academy of Sciences at Paris is to be the President of the General Conference of Weights and Measures. But this body will not be called into existence until the verification of all the new standards shall have been completed, when it will be convoked for the purposes of sanctioning them and their distribution. All the Governments who send delegates to the International Metric Commission will be entitled to be represented at the General Conference.

Articles 5 and 6 relate to the organisation of the International Bureau, the International Committee, and the Conference General. The duties of the International Bureau are specified as follows :- The verification and conscrvation of the new metric prototypes of the metre and kilogramme, the construction of which has been entrusted to the French Section of the International Metric Commission; the verification of all the copies of these prototypes and their periodical comparisons; the verification and comparison of geodesical measuring instruments ; and the comparison and verification of standards and scales of precision.

Articles 7,9 , and Io fix the establishment of the International Bureau and the mode of defraying the expenses by contributions from all the contracting governments, according to a scale based on the respective amounts of their actual population.

These expenses are limited by Articles 5 and 6 of the Regulations annexed to the Convention to the total amount of 400,000 irancs $(16,000 l$. $)$ for establishing the Bureau and providing it with all the requisite instruments, together with an annual sum not exceeding 100,000 francs $(4,000 \%)$ for the current expenditure, reducible to 50,000 francs $(2,000 \mathrm{l}$.), after the completion and distribution of the new national metric standards.

Articles II, I2, 13 of the Convention reserve the right to every other civilised state to take part in it, under specified conditions; and enable the contracting parties by common agreement to make all such modifications in the terms of the Convention as may be found by experience useful; they also allow any of the contracting parties to withdraw from the Convention at the expiration of a term of twelve years.

A series of Regulations are annexed to the Convention, which fix the details of the organisation of the International Bureau, and of the composition and functions of the International Metric Committee and of the General Conference. Some transitory provisions are also annexed, relating to the completion of the construction of the new standards by the French Section, and their verification and distribution; as well as the mode of constituting the new International Committee and the General Conference.

At the Conference, the sittings of which were continued during March and April 1875 , twenty of the principal civilised countries were represented, viz. :-Germany, Argentine Republic, Austria and Hungary, Belgium, Brazil, Denmark, Spain, United States of America, France, Great Britain, Greece, Italy, Holland, Peru, Pro tugal, Russia, Sweden and Norway, Switzerland, Turke;; and Venezuela.

The Convention was signed by the pienipotentiaries of seventeen of these countries. The Governments of three countries-Great Britain, Holland, and Greece-declined to take part in the Convention. They were willing to take part in it, and to contribute towards the experises of the International Bureau, if its objects were limited to the verification of the new metric standards and the custody and use of the new prototypes, but they refused to take part in a Convention which established a permanent international institution for other and larger scientific objects, and for promoting the propress of the Metric System.

Further grounds for the refusal of the British Government were that by the terms of the Convention the International Metric Commission, to which delegates from this country were appointed by the Government, was virtually suppressed, and its functions and duties transfarred to the new Committee; that the propagation of the metric system was declared to be one of the primary duties of the new General Conference, thus sanctioning the objectionable precedent of directly authorising a scientific body to interfere with national usages in countries where the metric system has not been adopted.

The result of their Governments declining to take part: in the Convention has been that the representatives of Great Britain and of Holland have been compelled to decline to act upon the new International Committee, which was fixed by the Convention to be formed of the twelve members of the Permanent Cominittee, with the addition of the representatives of Italy and Switzerland. The Committee now consists of the following tweive members, who are to have the direction of the Intcinational Bureau :-
General Ibañez,

Dr. Förster,

Dr. J. Herr,

M. Stas,

General Morin,

Prof. Hilgard,

Dr. Wild,

General Baron Wrede,

Prof. Broch,

Husny Bey,

Prof. Govi,

Dr. Hirsch,

$$
\begin{aligned}
& \text { representing Spain, Presi lint. } \\
& \text { Germany. } \\
& \text { Austria. } \\
& \text { Belgium. } \\
& \text { France. } \\
& \text { United States of America. } \\
& \text { Russia. } \\
& \text { Swedet. } \\
& \text { Norway. } \\
& \text { Turkey. } \\
& \text { Italy. } \\
& \text { Switzerland, Secretery. }
\end{aligned}
$$

Under the terms of the Convention, the ratifications were to be exchanged on Dec. 20,1875 , and the com:isittee to enter on their full functions on Jan. I, I876. Meatiwile, as soon as the provisional instrument of the Convention was signed by the plenipotentiaries on April 15 last, the Committee were authorised at once to constitute themselves and to make their preliminary arrangements. They accordingly held five meetings and elected their president and secretary, as already stated, and they provisionally appointed Prof. Govi director of the International Bureau. By Article 6 of the Regulations annexed to the Convention, the yearly salary of the secretary to the Committee is fixed at 6,000 francs $(240 l)$, and that of the director of the Bureau, who is to reside there, is fixed at 15,000 francs $(600 l)$. The Committee at the same time selected the Pavillon Breteuil in the park of St. Cloud as the site of the Bureau.

On Dec. 20,1875 , the representatives of eleven ont of the seventeen contracting Governments met at Versailles, and exchanged ratifications of the Convention. It was announced that the Governments of Austria and Hungary, the United States of America, and Portugal, had 
not yet been able to obtain the sanction of their Legislatures for the ratification of the Convention, and they requested further time for this purpose. The Argentine Republic and Venezuela also requested further time, and the requests were granted. Brazil alone declined to ratify the Convention and take part in its objects.

Before the adjournment of the late French National Assembly, they passed a law which was introduced by the French Government to grant the Pavillon Breteuil at St. Cloud, with some adjoining land, to the directors of the International Bureau for the purposes of this scientific institution, so long as it shall continue in existence.

The following appear to be the approximate proportions which the several contracting States will have to contribute towards the expenses of the new International Metric Bureau, based on Article 20 of the Regulations, by which the unit of contribution is to be determined from the population of each State, expressed in millions, and multiplied by the coefficient 3 for those countries where the metric system is adopted compulsorily; by 2 where it is adopted permissively ; and by $\mathrm{I}$ for other countries.

\begin{tabular}{|c|c|c|c|c|c|c|}
\hline \multirow[b]{2}{*}{ States. } & \multirow{2}{*}{ 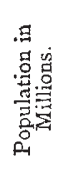 } & \multirow{2}{*}{ 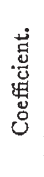 } & \multirow{2}{*}{ 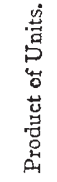 } & \multicolumn{3}{|c|}{ Approximate Contributions. } \\
\hline & & & & 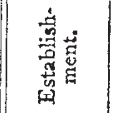 & 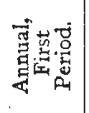 & 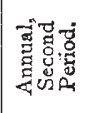 \\
\hline r. Germany & $4 . \mathrm{I}$ & 3 & $\mathrm{x} 23$ & $£ 2,353$ & $£ 5^{87}$ & $\$ 294$ \\
\hline 2. Argentine Republic & 2 & I & 2 & & & 5 \\
\hline $3 \cdot\left\{\begin{array}{lll}\text { Austria } & \ldots & \ldots \\
\text { Hungary } & \ldots & \ldots\end{array}\right.$ & $\begin{array}{l}20 \\
16\end{array}$ & 3 & $\left.\begin{array}{l}60 \\
48\end{array}\right\}$ & 2,066 & 516 & $25^{8}$ \\
\hline 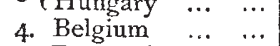 & 5 & $\begin{array}{l}3 \\
3\end{array}$ & $\begin{array}{l}407 \\
15\end{array}$ & 287 & 72 & 36 \\
\hline 5. Denmark $\ldots . .$. & 2 & $\mathrm{I}$ & 2 & $3^{S}$ & ro & 5 \\
\hline $\begin{array}{l}\text { 6. Spain } \ldots \text {.. } \ldots \\
\text { 7. United States of }\end{array}$ & 25 & 3 & 75 & $\mathbf{I}, 434$ & 358 & 179 \\
\hline America ... ... & 42 & 2 & 84 & $\mathrm{r}, 607$ & 402 & 201 \\
\hline 8. France $\quad \ldots \quad \ldots$ & 38 & 3 & $\mathrm{II}_{4}$ & $2,18 \mathrm{r}$ & 545 & 272 \\
\hline 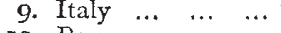 & 27 & 3 & $8 \mathbf{r}$ & $\mathrm{I}, 550$ & 387 & 194 \\
\hline xo. Peru $\ldots$... & 3 & 3 & 9 & 172 & 43 & $2 \pi$ \\
\hline I1. Portugal $\ldots$. & 7 & 3 & $2 \mathrm{I}$ & 402 & 100 & 50 \\
\hline 12. Russia... ... ... & $8_{3}$ & $\mathrm{I}$ & $8_{3}$ & 1,598 & 400 & 200 \\
\hline I3. Sweden & 4 & I & 4. & 76 & 20 & Io \\
\hline Norway $\ldots$ & 2 & I & 2 & $3^{8}$ & IO & 5 \\
\hline 14. Switzerland & 3 & 3 & 9 & $\begin{aligned} 172 \\
050\end{aligned}$ & 43 & $2 \mathrm{I}$ \\
\hline $\begin{array}{lll}\text { 15. Turkey } & \ldots & \ldots \\
\text { 16. Venezuela } & \ldots & \ldots\end{array}$ & $\begin{array}{r}38 \\
2\end{array}$ & $\begin{array}{l}3 \\
x\end{array}$ & $\begin{array}{r}102 \\
2\end{array}$ & $\begin{aligned} 1,950 \\
38\end{aligned}$ & $\begin{array}{rl}487 & 9 \\
10\end{array}$ & $\begin{array}{r}244 \\
5\end{array}$ \\
\hline & 360 & - & 836 &, 000 & $£ 4,000$ & $£ 2,000$ \\
\hline \multicolumn{4}{|c|}{ Approximate units of contribution } & Erg & $£ 5$ & $f 2$ I0 \\
\hline
\end{tabular}

If Great Britain had taken part in the Convention, the contribution from this country towards the expenses of establishing the International Bureau would have been about $600 l$., and towards the annual expenditure for the first period about $150 l$. a year.

The International Committee are now therefore in a position at once to commence operations. They are to meet at least once a year, and between their session can deliberate and pass resolutions by correspondence. They considered that at least a year must elapse from Jan. I, 1876 , before their new building and instruments will be ready for use. They therefore passed a resolution charging their executive to notify to the French Section. that the Committee would not be prepared to commence their comparisons and verifications of the new Metric Standards before the spring of 1877 . This will give plenty of time to the French Section to complete the construction of these new Standards and to make all such comparisons with the Standards of the Archives and with each other as may be necessary to ascertain their values with the requisite precision, before delivering the Standards to the International Committee for definitive verification.

H. W. Chisholm

\section{PHYSICAL SCIENCE IN SCHOOLS}

$\mathrm{I}^{\mathrm{T}}$ may contribute profitably to the discussion of the subject of :Physical Science in Schools, if I state briefly the experience of an effort, extending over twentyeight years, to give this subject a prominent, if not its merited place in our work. I may say that my boys rarely go to a university, and are almost wholly absorbed in professions, manufactures, and commerce.

Mr. Tuckwell's propositions (NATURE, vol. xiii., p. 4I2) are good, but perhaps the following modifications are be:ter :-

I. The business of a school is general education; the business of a university is special education.

2. The branches of study for the general education of a school should be Language, Mathematics, Natural Science, and Art.

3. Some knowledge of each of these should be imposed on every pupil; but each pupil should be allowed to apply himself chiefly to that branch of study for which he shows the most natural aptitude, and which therefore will to him be the best means of education.

4. The matriculation examinations for entrance to the universities should require a fixed standard of knowledge of all these branches of education; and give equal honours for excellence in either.

I think this would place science on an equal footing with language and mathematics, in both school and university, and would in due time relieve us of the conventional pedantry which regards language as the only sulficient standard of an educated man, and ignorance of the simplest elements of science as no disgrace.

Now for our own practice and experience. At nine or ten years of age our boys get simple lessons on wild fowers, which they collect, are taught to examine and describe, and write a simple account of ; necessary help of course being given.

On graduating to the upper school, which they do from ten to twelve years of age, they get three hours a week for descriptive lessons on botanical and zoological subjects, with reproductions and as much of classification as is practicable; and on meteorological phenomena and heat, illustrated by the daily and seasonal variations that affect themselves. The object here is to cultivate the observing powers, to induce discrimination of distinctive features, and to promote a thoughtful apprehension of the most easily discerned natural phenomena.

In the next grade four hours are given to science, and the study becomes more special. Mechanics is the subject taken, and if this subject be treated simply, and care be taken not to overrun the mathematical knowledge, it may be made sufficiently attractive, and a valuable means of thoughtful training in science.

In the next grade two hours a week are taken from mechanics, and chemistry is begun.

In the next grade the other two hours are taken from mechanics, and given to physiology-I. Vegetable; 2. Animal; so that the subjects here are physiology and chemistry with manipulation. In this grade, also, one hour a week is taken from the two commonly given to geography, and given to political economy. The boys in this grade will also often give special time to chemical manipulation, and to practical work in physiology. We have also workshops where a considerable amount of very good work in both wood and metal is regularly turned out, play time only being used.

It may be that I am rather exacting on my own efforts, but 1 have never been satisfied with our science teaching, and the current discussion of the subject in NATURE has added very materially to my dissatisfaction. To be dis- 